\title{
Enhancing the capability of rapid bridge replacement after extreme events
}

\author{
Yong Bai and Seong Hoon Kim \\ Department of Civil, Environmental, and Architectural Engineering, \\ The University of Kansas, Lawrence, Kansas, USA, and \\ William R. Burkett \\ Department of Engineering Technology and Civil Engineering, \\ Texas Tech University, Lubbock, Texas, USA
}

\begin{abstract}
Purpose - The potential threats of extreme events to highway bridges have received increased attention from government agencies, the engineering and construction communities, and the traveling public. These events include terrorist attacks as well as human-induced and natural hazards such as earthquakes, explosions, fires, floods, and hurricanes. To respond to the potential threats on highway bridges, a research project was conducted to identify rapid bridge replacement processes, techniques, and needs for improvements.

Design/methodology/approach - To achieve the research objectives, a detailed case study of previous bridge replacement following an extreme event was conducted. The case study was performed using a three-step approach. First, the research team reviewed the literature related to the case. Second, the research team interviewed the people who were involved with the case via the telephone. Third, the research team conducted a written survey to gain knowledge about the previously unanswered questions and additional information related to the case.

Findings - After studying the case, lessons learned were identified first. Then, the research team determined the processes that were used in the rapid bridge replacements and the needed improvements so that the research community could investigate new technologies to advance current practices.

Originality/value - The lessons learned could be of benefit to government agencies who are responsible for development of the enhanced emergency response plans for highway bridges, and engineering and construction communities who are responsible for design and reconstruction of the damaged bridges. The development of new technologies, if successful, will ultimately enhance the capability of rapid bridge replacement after extreme events.
\end{abstract}

Keywords Bridges, Case studies, Construction engineering, United States of America

Paper type Case study

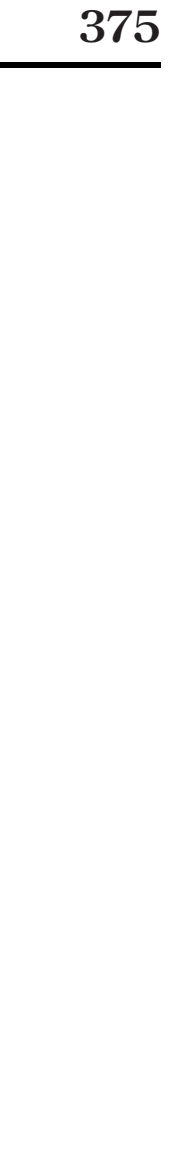

\section{Paper type Case study}




\section{ECAM}

14,4

376

\section{Introduction}

The terrorist attacks on September 11, 2001 and subsequent potential threats to the United States transportation systems have presented an urgent need to elevate the security of the transportation infrastructure and to enhance emergency management plans to quickly react to the possible consequences of extreme events. These events include terrorist attacks as well as human-induced and natural hazards such as earthquakes, explosions, fires, floods, and hurricanes. Highway bridges, as critical components of the transportation network, have been brought to closer attention by government agencies. A research project was conducted to identify rapid bridge replacement processes, techniques, and needs for improvements. One of the tasks associated with the research project was to perform a detailed case study, which was the replacement of the New York Thruway Interstate 87 (I-87) Bridge in Yonkers, New York. The I-87 Bridge incident provides useful lessons for government agencies and the engineering and construction communities that must plan for enhanced responses in case of future extreme events.

\section{Objectives and methodology}

The objectives of the research were to identify the processes and techniques to restore the use of a bridge quickly in the event it is damaged or destroyed and to determine the needs for future improvements. Case study methodology was utilized to accomplish these objectives. The replacement of I-87 Bridge was chosen for the case study because the bridge is in the major interstate highway system and the incident had significant impacts on the traveling public and surrounding communities.

The I-87 Bridge case study was performed using a three-step approach. First, the research team reviewed the literature related to the case including newspaper articles, conference and journal papers, technical reports, and web sites. Second, the research team interviewed the people who were involved with the case via the telephone. These people came from government agencies, design firms, contractors, and material suppliers. In these telephone interviews, people were asked a series of questions regarding their roles in the case and knowledge about the case. After the first two steps, the research team had an initial understanding about the case and unanswered questions were clearly outlined. The third step was to conduct a written survey to gain knowledge about the previously unanswered questions and additional information related to the case. The survey questionnaire consisted of five aspects including contracting method, engineering, construction, owner support, and material suppliers and vendors.

The rest of the paper is organized in the following manner. First, the current research efforts in the area of infrastructure security are briefly summarized. Second, the I-87 Bridge case is presented including the topics such as bridge incident, emergency plan and temporary traffic facility, design for replacement, bridge reconstruction, and lessons learned. Third, a general model for bridge replacement processes is generated based on results of the case study. Four, needs for future improvements are outlined in the area of rapid bridge replacement. These improvements will be accomplished through further research efforts. Finally, conclusions are presented in the last section. 


\section{Current research efforts}

Since the terrorist attacks on September 11 several research projects have been conducted to identify the infrastructure's vulnerabilities and to help government agencies develop or update the emergency management plans with the focus on mitigation, preparedness, response, and recovery. The American Association of State Highway and Transportation Officials (AASHTO) recognized the need to address the vulnerability assessment requirements for highway transportation, and sponsored the development of a guide for critical asset identification and protection (SAIC, 2002). Authors of this guideline divided vulnerabilities in highway transportation into the following three general categories:

(1) the physical facilities themselves (e.g. bridges, tunnels, roadways, and interchanges);

(2) the vehicles operating on the system; and

(3) the information infrastructure that monitors and manages the flow of goods, vehicles, and people on the highway system.

This Guide provides a starting point to identify and mitigate the vulnerability of and consequences to highway transportation assets from terrorist threats or attacks. A companion document, "A guide to updating highway emergency response plans for terrorist incidents," also funded by AASHTO and developed in parallel with the previous guide, assists government agencies in preparing and executing a coordinated emergency response to terrorist threats or attacks to the highway transportation system (Brinckerhoff, 2002). Besides these two guides, AASHTO sponsored another research project titled "Design of highway bridges for extreme events," which was supervised by the National Cooperative Highway Research Program. The objective of this research was to develop a design procedure for application of extreme event loads and combination loading to highway bridges (Ghosn et al., 2003).

State Departments of Transportation in the United States also initiated efforts to investigate and develop methods to lessen the impact of terrorist attacks and other extreme events on their transportation infrastructure. There are two recent research projects that concentrated on bridges. The objective of one project was to determine how bridges may be economically designed for security. Another project was to identify bridge replacement processes, techniques, and needs for improvements. The I-87 Bridge incident was chosen as a case study in the latter research project. The findings of this case study are presented as follows.

\section{I-87 Bridge incident case}

A gasoline tanker-truck traveled northbound on the Central Park Avenue in New York in the early morning on Thursday October 9, 1997. The driver was making a U-turn on the Central Park Avenue as it passed underneath the New York State Thruway I-87 Bridge and was hit from behind by a sedan traveling southbound on Central Park Avenue. After the collision, the gasoline truck exploded underneath the I-87 Bridge. The explosion caused a huge fire, which killed the sedan driver and damaged the overpass bridge on the Thruway. The bridge was 24.2 meters (79.3 feet) long and a total clear span from abutment to abutment was 23.2 meters (76.0 feet) without any intermediate piers.

\section{Rapid bridge replacement}


ECAM

14,4

\section{8}

Structural engineers assessed the damages and concluded that the bridge was unsafe for the traveling public (NYSTA, 1997a). This left the owner of the bridge, New York State Thruway Authority (NYSTA), no choice but to close the bridge immediately. The Thruway is one of the busiest commuting routes to New York City, which is used by 2,500 to 3,000 vehicles per hour in each direction in peak hours and 65,000 vehicles per day (Vero and Fay, 2000). Figure 1 shows the damaged I-87 Bridge.

\section{Emergency plan and temporary traffic facility}

Shortly after the incident, the NYSTA developed an emergency plan to handle the situation. The plan involved three major parts:

(1) establishing temporary traffic detour routes;

(2) demolition of the damaged bridge and replacing it with two two-lane temporary bridges; and

(3) replacing the bridge with a permanent structure (NYSTA, 1997a).

Southbound traffic had one existing lane through a service road. This lane was used as a detour immediately and was expanded to two lanes within the first three days. Also, detours were set the first day of incident for the northbound traffic.

The scene of an incident shall be protected for needed investigations, either criminal or non-criminal. This is particularly important if an incident is a terrorist attack. The engineering and construction communities must do everything possible to assist government agencies to investigate the causes of the incident. Contractors couldn't start the demolition of damaged bridge until the completion of the investigation.

For this case, demolition of the damaged bridge started immediately after the incident investigation to provide space for erection of two two-lane temporary bridges, one for southbound traffic and another for northbound traffic. NYSTA determined that the use of temporary bridges would be the fastest and best way to accommodate traffic

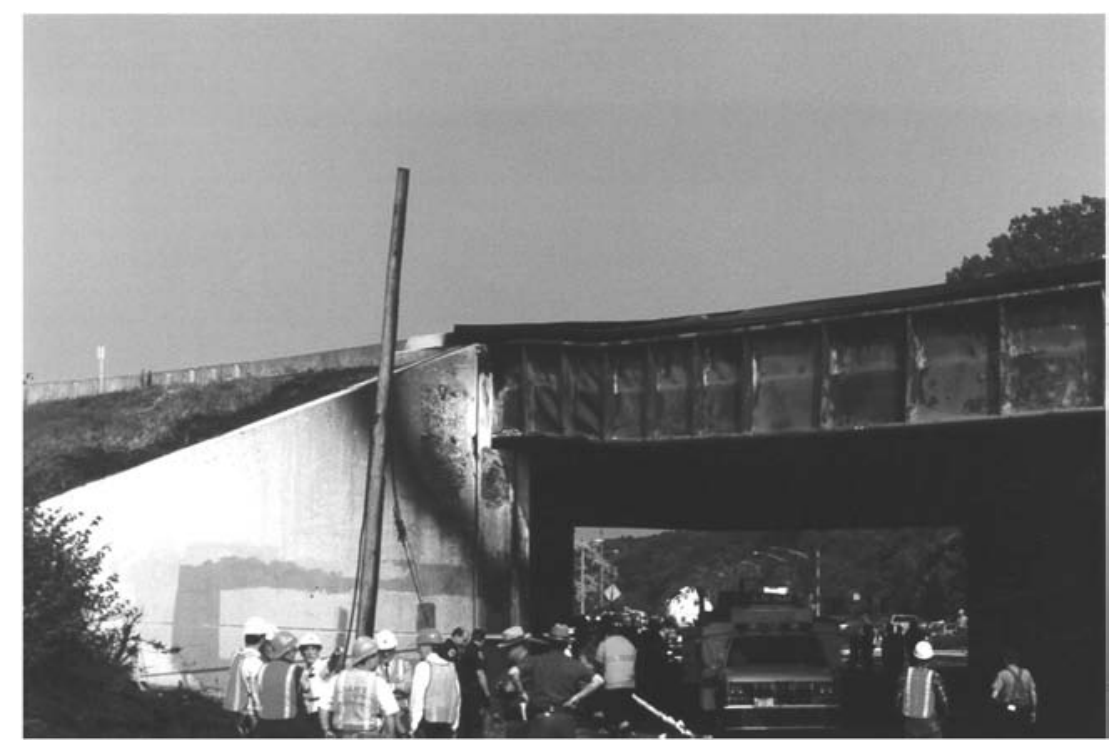

Figure 1.

Overview of the damaged I-87 Bridge 
while the permanent bridge was under construction. These temporary bridges, shown in Figure 2, were prefabricated steel truss structures similar to British Bailey Bridges that were developed during World War II for use in remote combat areas (Burkett et al., 2004). The southbound temporary bridge was about 44.8 meters (147 feet) long and the northbound bridge was about 47.2 meters (155 feet) long, spanning over the existing abutments, so that repair work on the permanent abutments could be done without interfering with the traffic above. The temporary bridges were shifted about three to five feet to the east and the supports of the bridges were built over the sidewalk of the Central Parkway Avenue. A ten-man crew assembled the temporary bridges and installed them using stationary launch rollers and a crane. The temporary bridges were ready for use by the traveling public in only 11 days (NYSTA, 1997b).

\section{Design for replacement}

To expedite the bridge replacement process and minimize impacts to the traveling public, the NYSTA decided to use the Inverset Bridge System that consists of modular pre-stressed bridge units containing a combined superstructure and deck as a single unit (Burkett et al., 2004). A total of 12 Inverset Units were used for the replacement of the I-87 Bridge. Each Inverset Unit was fabricated to cover the entire span but provided only a portion of the bridge's width and were installed side by side to complete the bridge's lateral dimension. Each modular unit was cast upside down with the steel I-beam supports on top and concrete deck cast on the bottom. After curing in a controlled inside environment, the completed unit was turned right side up and transported to the site for placement. At the site, the units were set with a crane onto the repaired bridge abutments.

The Inverset Units were designed jointly by the material supplier and the NYSTA Bridge Design Unit. Due to the emergency nature of the project, the development of the

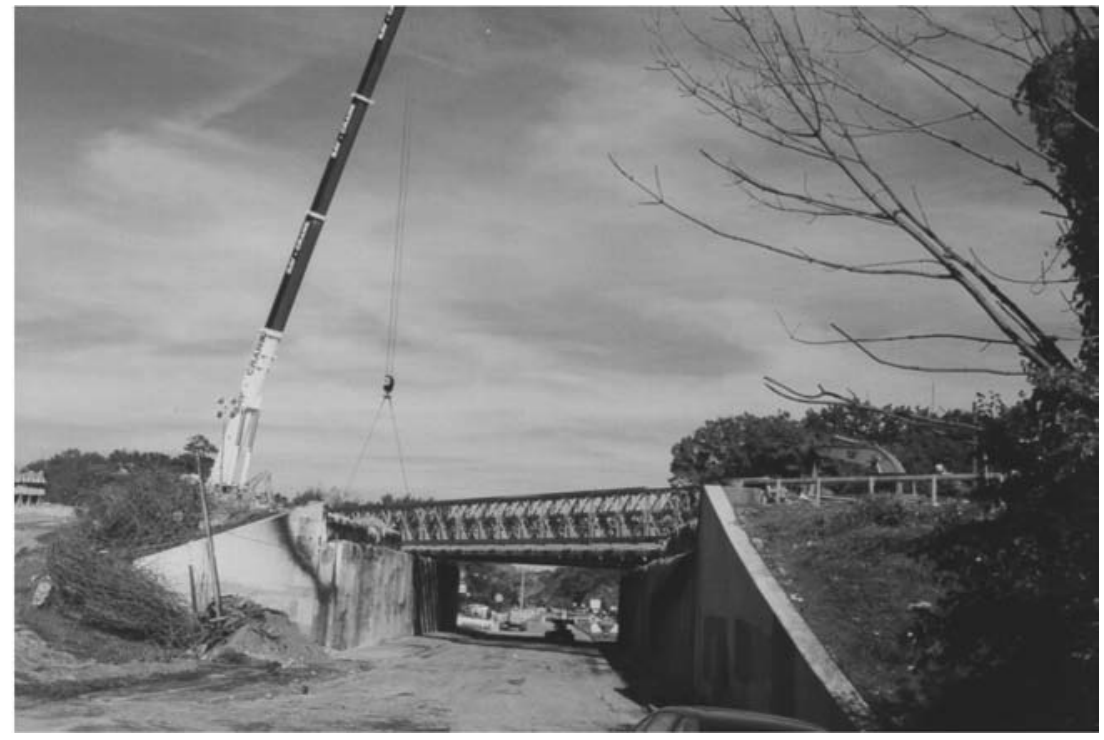

Rapid bridge replacement

379
Figure 2.

Two prefabricated steel truss bridges for temporary traffic detour 
ECAM

14,4

380 design and shop drawings were expedited along with the review and approval process by the NYSTA. The design and review process required very close coordination including hand-delivering submittals instead of using regular mails, single point of contact between design and reconstruction, and frequent conference calls to discuss progress and problem solve.

The Inverset Units were placed upon the existing repaired substructure. New pedestals were cast to fit the non-conventional spacing of the Inverset Units. Pre-cast parapets, which attached to the deck with bolts through the Inverset deck, were installed to expedite completion. The ends of the Inverset Units were modified to work as back walls to reduce the height of the abutments. Due to a large skew, this modification made a jointless bridge possible. This design detail was unique and made the bridge very simple, thus, reducing reconstruction time. Another important feature of the Inverset design was that the units were cast with an integral riding (sand blast form liner) finish. This allowed immediate use of the bridge that was installed in the winter months without the required waterproofing and asphalt overlays. Both waterproofing and overlays were installed the following summer. Besides waiving waterproofing and overlaying of the bridge deck as separate phases in the future, the design specifications also waived concrete curing duration based on cylinder tests results.

\section{Bridge reconstruction}

The reconstruction contract was awarded on October 31, 1997 (NYSTA, 1997c). A staged construction technique was implemented in order to minimize the disruption and inconvenience to the traveling public and surrounding community (Kulewicz et al., 1998). The first stage of reconstruction, which was started on November 29, 1997 and finished on December 8, 1997, was to rehabilitate the abutments. The fire caused the abutments to crack and delaminate. The surface concrete and front-face rebar were removed to a depth of $15.2 \mathrm{~cm}$ (6 inches) and replaced with a $27.9 \mathrm{~cm}$ (11 inches) high performance concrete facing. A thicker concrete overlay was required to achieve a thorough bond with the existing concrete. Since this was done under winter conditions, the entire concrete facing for the abutments had to be tented and heated to maintain curing temperatures. The second stage was to rebuild the southbound bridge using the first three Inverset Units that were delivered to the site on December 9, 1997. The two temporary prefabricated steel truss panel bridges had been installed on the far eastern portion of the abutments, leaving room for installation of the first three Inverset Units on the far western portion of the repaired abutments. About a week later, the second stage was completed, and southbound traffic was routed onto the new structure, allowing the removal of the southbound temporary bridge. During the third stage of the reconstruction, the second three Inverset Units were installed where the southbound temporary bridge had been removed. Construction of the permanent bridge continued until sufficient width was available to accommodate four lanes of traffic, two southbound and two northbound. At this point, the northbound traffic was rerouted from the temporary bridge onto the completed portion of the permanent bridge, and the northbound temporary bridge was removed. During the last stage of reconstruction, the remaining portion of the bridge (northbound) was completed including the installation of the last six Inverset Units, approach slabs, and the pre-cast 
barrier parapet. The last Inverset Units was set on February 10, 1998. Figure 3 presents the timeline of major activities in the replacement of the I-87 Bridge.

The NYSTA inspected the fabrication of the Inverset Units in the fabrication shop. The Units were fabricated and later installed in accordance with the New York State Department of Transportation (NYSDOT) Inverset specification, which had been adopted before this incident. All other NYSDOT's specifications were also followed during reconstruction. Using Inverset Units, easy and simple design, and emergency bid provisions saved valuable reconstruction time and reduced the impact on the traveling public and surrounding communities. The bridge replacement was completed on February 26, 1998, just four-and-a-half months after the incident (NYSTA, 1998). Under normal conditions, it would take approximately two years to replace the damaged bridge. The contract specified a $\$ 5,000$ per day bonus/penalty for early/late completion with a $\$ 50,000$ cap for either scenario. The contractor received a $\$ 40,000$ bonus (8 days at $\$ 5,000 /$ day) for early completion of the project (New York Times, 1998).

Reconstruction of the bridge required lane restrictions and some infrequent closures on Central Park Avenue, which runs underneath the bridge. To minimize the impact on the public, work activities were scheduled between rush hours and construction was avoided on holidays and weekends. Closures of Central Park Avenue were limited to times necessary to erect the new structures. Short-term traffic stoppages, not to exceed five minutes, occurred at various times throughout the reconstruction process. Pedestrian traffic was maintained on Central Park Avenue, except at infrequent times.

\section{Lessons learned}

There were many factors contributing to the success for the replacement of the I-87 Bridge. In order to document what can be learned from this extreme event, the research team conducted this case study. During the study, the research team reviewed literature (including information posted on web sites), interviewed people who were involved in the replacement of the bridge, and performed written surveys. Notwithstanding its terrible consequences, the I-87 Bridge tragedy provides useful lessons for government agencies, and the engineering and construction communities that must plan for enhanced responses during future extreme events. The following is a summary of lessons learned from this extreme event:

\begin{tabular}{|l|c|c|c|c|c|c|c|c|c|c|}
\hline \multicolumn{1}{|c|}{ Major Activities } & $10 / 9 / 97$ & $10 / 20 / 97$ & $10 / 31 / 97$ & $11 / 29 / 97$ & $12 / 8 / 97$ & $12 / 9 / 97$ & $12 / 16 / 97$ & $1 / 12 / 98$ & $2 / 10 / 98$ & $2 / 26 / 98$ \\
\hline Incident date & 4 & & & & & & & & & \\
\hline $\begin{array}{l}\text { Demolition \& installation of } \\
\text { temporary bridges }\end{array}$ & & & & & & & & & & \\
\hline $\begin{array}{l}\text { Awarding reconstruction } \\
\text { contract }\end{array}$ & & & - & & & & & & & \\
\hline Abutment rehabilitation & & & & - & & & & & & \\
\hline $\begin{array}{l}\text { Construction of the first 3 } \\
\text { Inverset Units }\end{array}$ & & & & & & & & & & \\
\hline $\begin{array}{l}\text { Construction of the second 3 } \\
\text { Inverset Units }\end{array}$ & & & & & & & & & & \\
\hline $\begin{array}{l}\text { Construction of the last 6 } \\
\text { Inverset Units }\end{array}$ & & & & & & & & & & \\
\hline Bridge Replacement Complete & & & & & & & & & & $\Lambda$ \\
\hline
\end{tabular}

Rapid bridge replacement

381 
ECAM

14,4

\section{2}

- Using the Inverset Bridge System shortened the bridge reconstruction process. The NYSTA saved considerable time by ordering the Inverset Units, the long-lead-time items, before awarding the reconstruction contract. In addition, NYSDOT had adopted Inverset specifications before the incident that made the implementation easier to carry out.

- Since the Inverset Units were produced inside the fabrication plant, winter weather had no impact on Units production and delivery. This was very critical to the rapid bridge replacement.

- Using the staged construction technique minimized the disruption and inconvenience to the traveling public and surrounding communities during the replacement project. Work activities were scheduled between rush hours and construction was avoided on holidays and weekends. The entire operation was conducted in an orderly fashion.

- The NYSTA's willingness to expedite the shop drawing review and approval process was very critical to the effectiveness of the bridge replacement.

- Partnerships among the owner, the material suppliers, and the contractors established during the bridge replacement, built trust, reduced conflicts, and helped overcome bureaucratic obstacles and other adversities typically associated with this type of emergency project.

\section{Bridge replacement process}

A general model used to represent the rapid bridge replacement processes was developed through this case study, shown in Figure 4. The model includes three key elements:

(1) major players;

(2) major tasks; and

(3) major decisions.

Major players are parties such as bridge owners, design firms, contractors, material suppliers, and vendors, who have the responsibility to conduct the bridge replacement tasks and make major decisions during the bridge replacement process. Major tasks of bridge replacement include traffic detour, demolition, design, contract, and reconstruction. At each stage, major decisions need to be made, which have significant impacts on the outcomes of bridge replacement. For example, during the design stage, the most important decision is to decide whether the bridge shall be rebuilt using an identical structure or a new structure. If the decision is to use the identical structure, then the design work is simple if the original drawings and specifications are archived. In some cases, using the identical structure may not be the best way to replace a bridge quickly. This was the case for the I-87 Bridge in New York. 


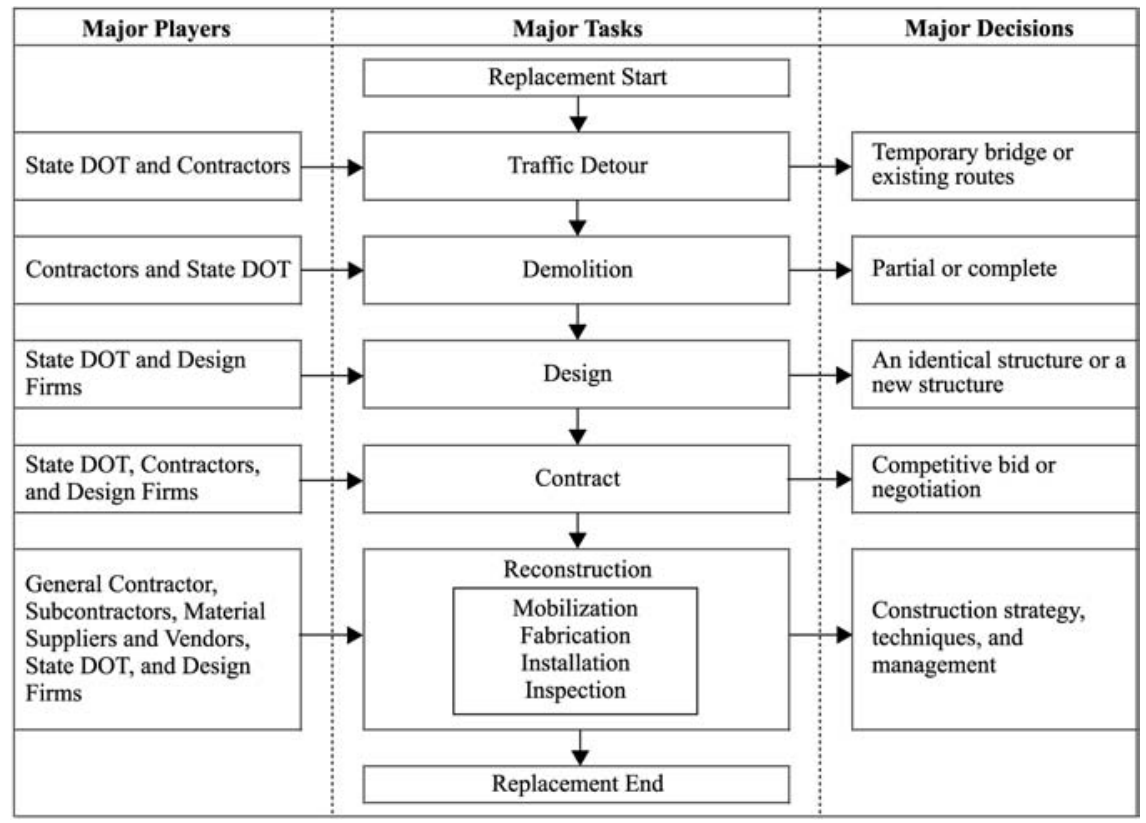

Rapid bridge
replacement

383

Engineers from several government agencies, design firms, and construction companies agreed that the replacement processes for the engineering and construction communities to replace a damaged bridge are basically the same regardless types of extreme events. Examples of these events may include earthquakes, explosions, fires, floods, and hurricanes.

\section{Need for improvements}

Bridge replacement is a complicated operation that involves many parties. It requires each party to make technical and management decisions at different stages in a very short period of time. Traditionally, each party makes decisions that best suit its interests, known as activity-level interest. However, meeting the activity-level interest may not lead to the best solution for the overall replacement project, known as project-level interest. The major challenges of achieving project-level interest for bridge replacement are communication and coordination among parties involved in the replacement process. Currently, there is no system that coordinates the different parties' tasks through gathering, processing, manipulating, storing, and distributing required information/data during the replacement process for decision-making purposes. Poor communication and coordination could result in cost overruns and inaccurate construction schedule forecasts. For example, nobody could tell that the reconstruction of I-87 Bridge would be ahead of schedule until the very end of the project. Although the replacement was finished ahead of the original schedule, the process clearly indicated that an accurate and reliable schedule was unable to be produced and provided to the major players and general public based on the existing construction technologies. 
ECAM

14,4

384
To enhance the capability of rapid bridge replacement after extreme events, there is an urgent need to develop new technologies to address the challenges mentioned above. Currently, the research team is developing a wireless real-time productivity measurement system which includes a video camera, a data processor, an AC transformer, two antennas, and a laptop computer, see Figures 5 and 6 . This system is designed to measure the construction crew productivity at the bridge site without interfering with construction operations. The technology underneath the system is based on time study theory that has proved for many years to be a very effective means for analyzing work-face activities. However, the traditional time study is

Figure 5.

Major components of the wireless real-time productivity measurement system

Figure 6.

Framework for the wireless real-time productivity measurement system
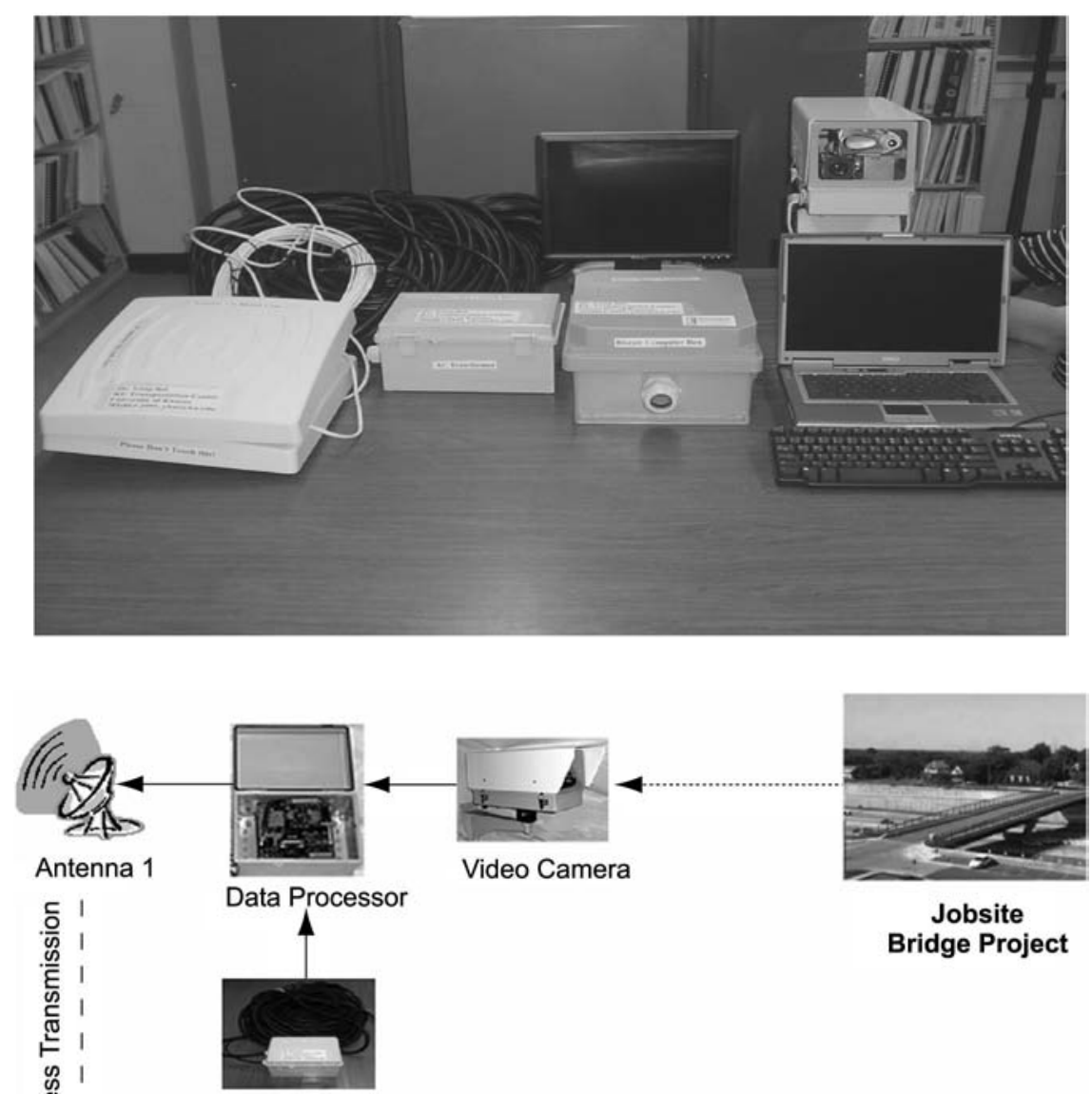

AC Transformer 
conducted by employing additional people to manually collect data at the construction sites. As a result, the traditional method increases the cost, delays the analyses, and interferes with crew activities that may produce inaccurate data. The wireless real-time system overcomes these shortfalls. Using the real-time productivity data, engineers and project managers may be able to accurately determine the bridge replacement progress and easily share the information with all parties involved in the bridge replacement project. Thus, the wireless real-time productivity measurement technology has a great promise to address communication and coordination issues, to control cost overruns, to improve construction schedule forecasts, and to increase emergency response capability after extreme events. The performance of the system will be determined in the field experiments and results will be reported in the near future.

\section{Conclusions}

After the terrorist attacks on September 11, 2001, bridge replacements after extreme events have been brought to closer attention by government agencies and the engineering and construction communities. A research project was conducted to identify bridge replacement processes, techniques, and needs for improvements through a detailed case study, which was the replacement of the I-87 Bridge in New York. The bridge superstructure was totally damaged due to a huge fire caused by a collision between a gasoline truck and a sedan, and was replaced under an emergency situation. The identified processes of the bridge replacement included temporary traffic management (e.g. setup detour routes and temporary bridges), demolition of the damaged structure, design for replacement, contracting, and bridge reconstruction. During the replacement processes, various construction engineering and management techniques were employed to minimize impacts to the traveling public and surrounding communities and accelerate overall replacement schedules. These techniques are:

- using prefabricated steel truss panel bridges for temporary traffic;

- utilizing prefabricated Inverset Units for the bridge superstructure;

- employing stage construction;

- having an incentive/disincentive clause in the construction contract; and

- changing normal operational procedures.

Because of these techniques, the I-87 Bridge was replaced just four-and-a-half months after the incident. Under normal conditions, it would have taken approximately two years. Although the replacement project was finished ahead of the original schedule with a good quality and safety record, there are areas that could be improved in the future to make the replacement process even better. In specific, there is a need to develop new technologies to integrate and coordinate different parties' tasks through gathering, processing, manipulating, storing, and distributing required information/data during the replacement processes for decision-making purposes. If the development of new technologies is successful through further research efforts, the implementation of such new technologies will improve communication and coordination among parties involved in the bridge replacement processes. As a result, it will enhance the capability of rapid bridge replacement after extreme events.

\section{Rapid bridge replacement}

385 
ECAM

14,4

386

\section{References}

Brinckerhoff, P. (2002), “A guide to updating highway emergency response plans for terrorist incidents”, contractor's final report, Parsons Brinckerhoff-PB Farradyne, Rockville, MD.

Burkett, W.R., Nash, P.T., Bai, Y., Hays, C. and Jones, C. (2004), "Rapid bridge replacement techniques", report number 0-4568-1, Texas Department of Transportation, Austin, TX.

Ghosn, M., Moses, F. and Wang, J. (2003), "Design of highway bridges for extreme events", National Cooperative Highway Research Program, Report No. 489, TRB, Washington, DC.

Kulewicz, M.J., Giles, K., Marcelle, J., Smith, P.J. and Baker, A. (1998), "New York State Thruway bridge story", Proceedings of Invisible Construction Conference, Institute for Civil Infrastructure Systems, New York University, New York, NY.

New York Times (1998), "Fast and convenient repairs", New York Times, (Editorial), March 12.

NYSTA (1997a), “Thruway announces Yonkers Overpass Plan”, news release, New York State Thruway Authority, Albany, NY, October 9.

NYSTA (1997b), “Governor Pataki opens temporary Thruway bridges in Yonkers", news release, New York State Thruway Authority, Albany, NY, October 20.

NYSTA (1997c), "Thruway Authority awards contract for replacement of Yonkers Bridge”, news release, New York State Thruway Authority, Albany, NY, November 6.

NYSTA (1998), “Governor Pataki opens new Thruway bridges at Yonkers”, news release, New York State Thruway Authority, Albany, NY, February 25.

Science Applications International Corporation (SAIC) (2002), "A guide to highway vulnerability assessment for critical asset identification and protection”, contractor's final report, Science Applications International Corporation, Transportation Policy and Analysis Center, Vienna, VA.

Vero, A. and Fay, S. (2000), "Team effort brings replacement to reality", Rehabilitation, January/February.

\section{Corresponding author}

Yong Bai can be contacted at: ybai@ku.edu

To purchase reprints of this article please e-mail: reprints@emeraldinsight.com Or visit our web site for further details: www.emeraldinsight.com/reprints 